\title{
INFLUENCE OF Sn AND Pb IONS SUBSTITUTIONS ON DIELECTRIC PROPERTIES OF BARIUM TITANATE
}

\begin{abstract}
The results of the microstructural and dielectric measurements of $\left(\mathrm{Ba}_{1-x} \mathrm{~Pb}_{\mathrm{x}}\right)\left(\mathrm{Ti}_{1-\mathrm{x}} \mathrm{Sn}_{\mathrm{x}}\right) \mathrm{O}_{3}(\mathrm{BPTS} x)(x=0,0.05,0.10,0.30)$ polycrystalline samples are presented. The samples were obtained by means of a high temperature synthesis and their expected stoichiometry was confirmed by energy dispersive spectroscopy (EDS) measurements. The dielectric properties of BPTS $x$ were studied with the use of broadband dielectric spectroscopy. The measurements over a wide range of temperature (from $140 \mathrm{~K}$ to $600 \mathrm{~K}$ ) and frequency (from $0.1 \mathrm{~Hz}$ to $10 \mathrm{MHz}$ ) were performed. The experimental results indicate an influence of $\mathrm{Pb}$ ions in a sublattice $\mathrm{A}$ and $\mathrm{Sn}$ ions in a sublattice $\mathrm{B}$ substitution on paraelectric - ferroelectric phase transition parameters. Diffused phase transitions from a paraelectric to ferroelectric state (for $x=0.10$ and $x=0.30$ ) were observed. From the electric modulus measurements in the frequency domain the relaxation times and the activation energy were determined.
\end{abstract}

Keywords: barium titanate ceramics, dielectric properties, phase transition

\section{Introduction}

Barium titanate $\mathrm{BaTiO}_{3}(\mathrm{BT})$ and lead titanate $\mathrm{PbTiO}_{3}$ (PT) are the most common perovskite ferroelectric materials. The biggest advantage of these materials is a wide possibility of modification their physical properties by ferroactive and nonferoroactive ions substitutions in the perovskite A and/or B sublattices [1-6]. The popularity of solid solutions based on BT and PT are growing due to their good parameters, which gives a possibility of their wide technical applications, especially in electronics and optoelectronics. The strong modifications of the physical properties were obtained by a substitution of $\mathrm{Sn}$ ions in a sublattice B in BT [7-9]. The previous publications, concerning the investigation of physical properties of perovskite structure solutions with Sn ions substitutions, point out a possibility of their applications in actuators, capacitors, small sized devices, and multilayer ceramic capacitors [1012]. An influence of $\mathrm{Pb}$ ions substitutions in a sublattice $\mathrm{A}$ and $\mathrm{Sn}$ ions in a sublattice B on the dielectric properties and the phase transition characters in barium titanate was investigated. The aim of these studies was to obtain a functional material of appropriate microstructure and diffusion of paraelectricferroelectric phase transition. This material should have stable electrical characteristics over a wide temperature range.

\section{Experimental}

The polycrystalline samples of $\left(\mathrm{Ba}_{1-\mathrm{x}} \mathrm{Pb}_{\mathrm{x}}\right)\left(\mathrm{Ti}_{1-\mathrm{x}} \mathrm{Sn}_{\mathrm{x}}\right) \mathrm{O}_{3}$ for $\mathrm{x}=0,0.05,0.10$ and 0.30 (abbreviated to BPTS5, BPTS10 and BPTS30) were obtained by mean of a high temperature synthesis $(1300 \mathrm{~K})$ and sintering $(1700 \mathrm{~K})$. Barium oxalate, lead oxalate, titanium oxide and tin oxide were used as starting materials. A quality of the obtained material was checked by means of a scanning electron microscope (SEM), and the designed composition was confirmed by an EDS spectroscopy method.

Dielectric measurements were carried out with the use of a broadband dielectric spectroscopy at the temperature ranging from $140 \mathrm{~K}$ to $600 \mathrm{~K}$ and at frequency ranging from $0.1 \mathrm{~Hz}$ to $10 \mathrm{MHz}$. The Quatro Cryosystem temperature controller together with an Alpha-AN High Performance Frequency Analyzer system WinDETA Novocontrol software was used.

\section{Results and discussion}

The images of the fractures of the investigated samples at $1000 \times$ magnification are shown in Fig. 1. The surface of the fracture goes along the grains as well as along the boundaries between the grains. In the grains a tendency to the formation of crystalline structure is observed. A good homogeneity of the microstructures and a small degree of porosity were noted. The pores had an irregular shape without curvings and narrowings. The growth terraces of grains are clearly seen. They indicate that the growth of grains proceeds according to a layer mechanism with a screw dislocations [13].

\footnotetext{
* PEDAGOGICAL UNIVERSITY, INSTITUTE OF PHYSICS, PODCHORAŻ̇YCH 2, 30-084 CRACOW, POLAND

** PEDAGOGICAL UNIVERSITY, INSTITUTE OF ENGINEERING, PODCHORĄŻYCH 2, 30-084 CRACOW, POLAND

*** UNIVERSITY OF SILESIA IN KATOWICE, INSTITUTE OF TECHNOLOGY AND MECHATRONICS, ŻYTNIA 12, 41-200 SOSNOWIEC, POLAND

\# Corresponding author: wbak@up.krakow.pl
} 
a)

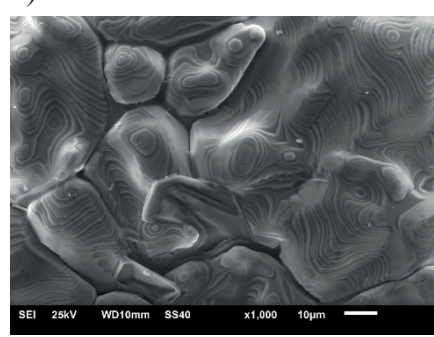

b)

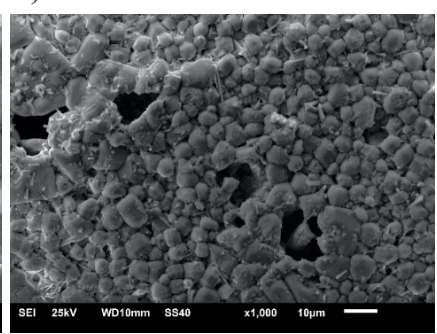

Fig. 1. SEM micrograph for BT (a) and BPTS30 (b) samples

The temperature dependences of the real part of the dielectric permittivity ( $\left.\varepsilon^{\prime}\right)$ are shown in Fig. 2. The $\mathrm{Pb}$ and $\mathrm{Sn}$ ions substitutions in BPTSx solid solution cause the paraelectric-ferroelectric (PE-FE) phase transition temperature decrease.

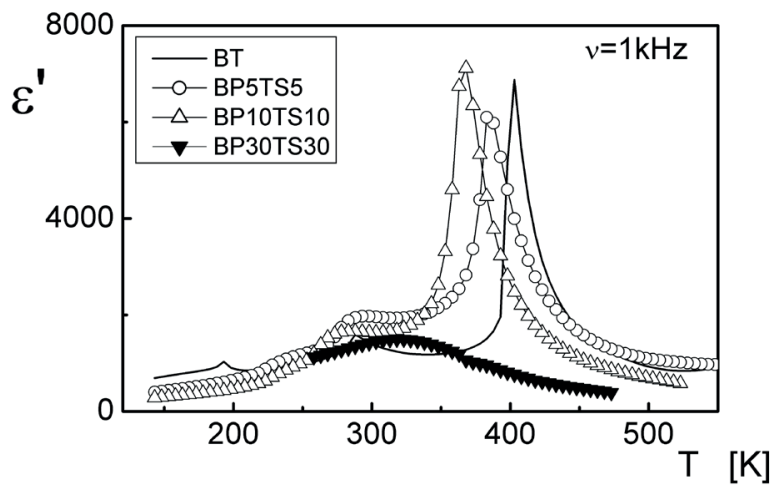

Fig. 2 Temperature dependence of the real part of dielectric permittivity $\varepsilon$ ' for BT, BPTS5, BPTS10 and BPTS30 samples

One can see a slightly diffused PE-FE phase transitions for $x=0,0.05$ and 0.10 . For BPTS30 sample (Fig. 3.) all structural transitions "overlap" to form a strong diffuse of PEFE phase transition [14].

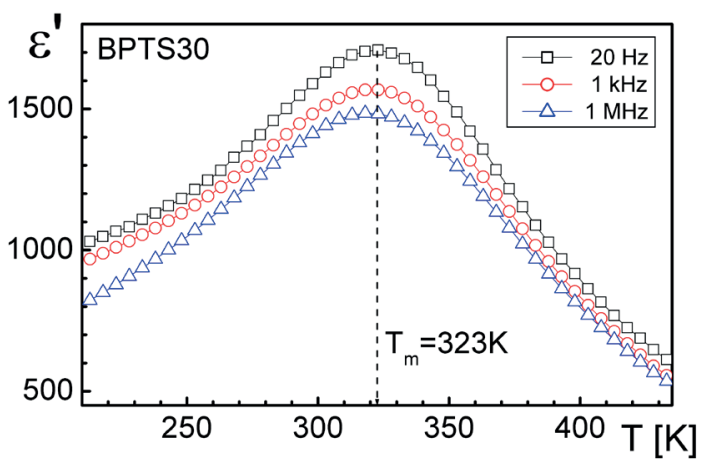

Fig. 3. Temperature dependence of the real part of dielectric permittivity $\varepsilon$ ' for BPTS30 at the frequency of $20 \mathrm{~Hz}, 1 \mathrm{kHz}$ and $1 \mathrm{MHz}$

The temperature $T_{\mathrm{m}}=323 \mathrm{~K}$ corresponding to the maximum of the $\varepsilon_{\mathrm{m}}^{\prime}$ depending on the electric field frequency for this sample was constant. The increase of $\mathrm{Pb}$ and $\mathrm{Sn}$ ions concentration (up to $x=0.30$ ) in BPTSx solid solution did not change the nature of the phase transition from a diffuse transition to a transition of relaxor type. The characteristic feature of relaxor behavior is the dependence of the temperature $\mathrm{T}_{\mathrm{m}}$ on electric field frequency and the shift of $\varepsilon_{\mathrm{m}}{ }_{\mathrm{m}}$ to higher temperatures with increasing frequency. The (Eq.1) describes ferroelectric materials with diffuse phase transition:

$$
\frac{1}{\varepsilon}=\frac{1}{\varepsilon_{m}}+A\left(T-T_{m}\right)^{\gamma}
$$

The $\gamma$ parameter values obtained from the Curie-Weiss law are presented in Fig. 4. The value close to 1 (BPTS5) indicates a very weak diffusion of the PE-FE phase transition. For BPTS30 sample the value of $\gamma$ is 2.00. This indicates an increase in the diffusion of the phase transition with the increasing $\mathrm{Pb}$ and $\mathrm{Sn}$ ions concentration.

The electric modulus $M^{*}$ and complex permittivity $\varepsilon^{*}$ are related by the following formula: $M^{*}=1 / \varepsilon^{*}=M^{\prime}+i M^{\prime \prime}$. The dependence of imaginary part of the electric modulus ( $M$ ') on frequency at selected temperature for BPTS5 sample is presented in Fig. 5

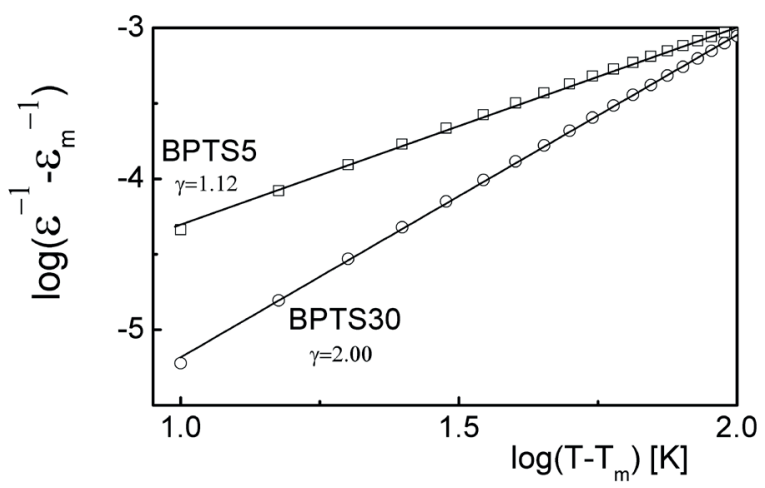

Fig. 4. The dependences of $\log \left(\varepsilon^{-1}-\varepsilon_{m}^{-1}\right)$ vs. $\log \left(T-T_{m}\right)$ at $1 \mathrm{MHz}$ for BPTS5 and BPTS30 samples

The increase in temperature cause the increase of the $M$ " peak values and the shift of the curves towards higher frequencies. On the basis of the data presented in Fig. 5 the relaxations times were calculated using the $\omega \tau=2 \pi \nu_{m} \tau=1$ equation, where $v_{m}$ - value of frequency for the $M$ " peaks at fixed temperature.

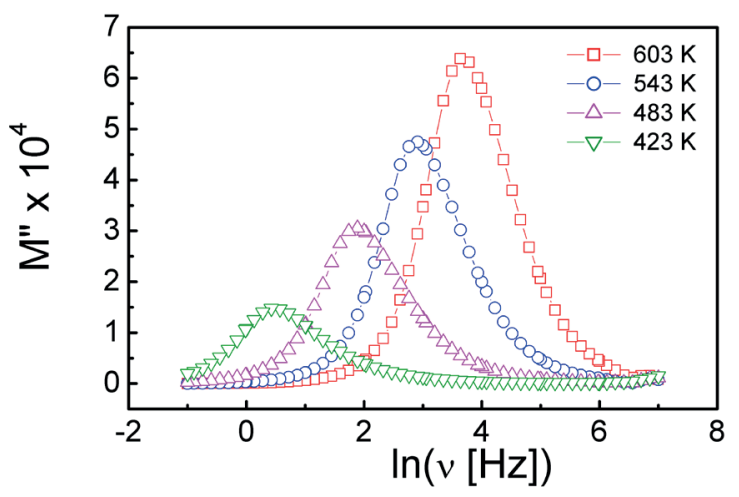

Fig. 5 The imaginary part of electric modulus $M^{\prime \prime}$ as a function of frequency for different temperatures for BPTS5 sample 
The collected results are presented in the form of $\tau(1000 / T)$ plots (Fig. 6). The thermal activation energies in the paraelectric phase for BPTS5 and BPTS10 samples are similar. The increase in the concentration of $\mathrm{Pb}$ and $\mathrm{Sn}$ ions in the BPTSx samples causes the increase of the relaxation time which may be related to transport of electric charge both in grains and grain boundaries.

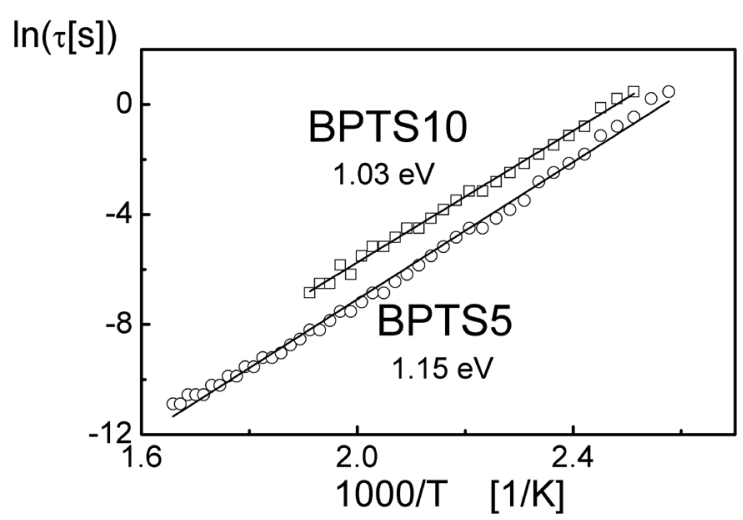

Fig. 6 The relaxation times as a function of 1000/T for BPTS5 and BPTS10 samples

\section{Conclusions}

The simultaneous substitutions of $\mathrm{Pb}$ ions (sublattice $\mathrm{A}$ ) and $\mathrm{Sn}$ ions (sublattice B) cause both a decrease in the temperature of paraelectric-ferroelectric phase transition and the increase in its diffusion. The change of nature of PE-FE phase transition generally depends on the cationic sublattice in which ions are substituted and on these ions concentration. The temperature dependences of the electric permittivity for BPTSx samples (for $x=0$ and $x=0.05$ ) indicate the occurrence of slightly diffused PE-FE phase transition whereas for $x=0.10$ and $x=0.30 \mathrm{DPT}$ are observed. The strong phase transition diffusion for BPTS30 sample in the range of temperatures close to room temperature makes this material very attractive for various technical applications. The imaginary part of electric modulus measurements made it possible to estimate the relaxation times $\tau$ and the thermal activation energy of the paraelectric phase. The values of these energies are typical for electron transport in semiconducting materials.

\section{REFERENCES}

[1] D. Czekaj, Fabrication and study of BST - based functional materials, University of Silesia, Gnome Publishing House, Katowice 2010.

[2] D. Czekaj, A. Lisińska-Czekaj, Influence of Mg-doping on synthesis of sol-gel derived BST thin films, Journal of Advanced Dielectrics 2/1, 1250010 (2012).

[3] E.G. Fesenko, A. Lisińska-Czekaj, D. Czekaj, Z. Surowiak, $\mathrm{g}$-radiation effect on domain and defect structure of $\mathrm{BaTiO}_{3}$ crystals, Proc. of SPIE (USA) 5136, 72-77 (2004).

[4] Y. Zu, C. Ang, R. Guo, A.S. Bhalla, Dielectric properties of $\mathrm{BaTi}_{1-\mathrm{x}} \mathrm{Zr}_{\mathrm{X}} \mathrm{O}_{3}$ solid solutions, Mat. Lett. 61, 326-329 (2007).

[5] C. Kajtoch, Influence of Zr-substitution on phase transitions character in polycrystalline $\mathrm{Ba}\left(\mathrm{Ti}_{1-\mathrm{x}} \mathrm{Zr}_{\mathrm{x}}\right) \mathrm{O}_{3}$, J. Mater. Sci. 46, 1469-1473 (2011).

[6] B.Garbarz-Glos, W. Piekarczyk, I. Smeltere, W. Śmiga, M. Antonova, Ultrasonication as a method of investigation of the mechanical properties of doped hafnium barium titanate Ferroelectrics. 436, 87-95 (2012).

[7] C. Kajtoch, W. Bąk, B. Garbarz-Glos, Study of the Phase Transition in Polycrystalline $\mathrm{Ba}\left(\mathrm{Ti}_{0.90} \mathrm{Sn}_{0.10}\right) \mathrm{O}_{3}$, Ferroelectrics 464, 8-14 (2014).

[8] W. Bąk, C. Kajtoch, F.Starzyk, Dielectric properties of $\mathrm{BaTi}_{1-\mathrm{x}} \mathrm{Sn}_{\mathrm{x}} \mathrm{O}_{3}$ solid solution, Mat. Sci. Eng. B-solid. 100, 9-12 (2003).

[9] C. Kajtoch, Dielectric properties of $\mathrm{Ba}\left(\mathrm{Ti}_{1-\mathrm{x}} \mathrm{Sn}_{\mathrm{x}}\right) \mathrm{O}_{3}$ ceramics in the paraelectric phase, Ceram. Int. 37, 387-391 (2011).

[10] Line ME, Glass AM: Principles an aplications of ferroelectrics and related materials. Oxford: Clarendon Press 1977.

[11] J.C. Burfoot, G.W. Taylor, Polar dielectrics and their applications. London: Macmillan Press 1979.

[12] K. Uchino, Ferroelectric devices. New York, CRC Press 2009.

[13] W.E. Lee, M.W. Rainforth, Ceramic Microstructures: Property Control by Processing. London: Chapman\&Hall 1994.

[14] D. Ziętek, Diffused phase transition in polycrystalline $\left(\mathrm{Ba}_{0.70} \mathrm{~Pb}_{0.30}\right)\left(\mathrm{Ti}_{0.70} \mathrm{Sn}_{0.30}\right) \mathrm{O}_{3}$ Tech. Transactions Chemistry, 1-Ch, 149-155 (2014). 
